\title{
Lysozyme transgenic goats' milk positively impacts intestinal cytokine expression and morphology
}

\author{
Caitlin A. Cooper • Dottie R. Brundige • \\ Wade A. Reh • Elizabeth A. Maga • \\ James D. Murray
}

Received: 29 October 2010/Accepted: 20 January 2011/Published online: 11 February 2011

(C) The Author(s) 2011. This article is published with open access at Springerlink.com

\begin{abstract}
In addition to its well-recognized antimicrobial properties, lysozyme can also modulate the inflammatory response. This ability may be particularly important in the gastrointestinal tract where inappropriate inflammatory reactions can damage the intestinal epithelium, leading to significant health problems. The consumption of milk from transgenic goats producing human lysozyme (hLZ) in their milk therefore has the potential to positively impact intestinal health. In order to investigate the effect of hLZ-containing milk on the inflammatory response, young pigs were fed pasteurized milk from hLZ or non-transgenic control goats and quantitative realtime PCR was performed to assess local expression of TNF- $\alpha$, IL- 8 , and TGF- $\beta 1$ in the small intestine. Histological changes were also investigated, specifically looking at villi width, length, crypt depth, and lamina propria thickness along with cell counts for intraepithelial lymphocytes and goblet cells. Significantly higher expression of anti-inflammatory cytokine TGF- $\beta 1$ was seen in the ileum of pigs fed pasteurized milk containing hLZ $(P=0.0478)$, along
\end{abstract}

C. A. Cooper - D. R. Brundige - W. A. Reh ·

E. A. Maga · J. D. Murray $(\bowtie)$

Department of Animal Science, University of California, Meyer Hall, One Shields Avenue, Davis, CA 95616, USA e-mail: jdmurray@ucdavis.edu

J. D. Murray

Department of Population Health and Reproduction, University of California, Davis, CA 95616, USA with an increase in intraepithelial lymphocytes $(P=0.0255)$, and decrease in lamina propria thickness in the duodenum $(P=0.0001)$. Based on these results we conclude that consuming pasteurized milk containing hLZ does not induce an inflammatory response and improves the health of the small intestine in pigs.

Keywords Lysozyme - Cytokines - Transgenic goats · Intestine $\cdot$ Inflammation $\cdot$ TGF- $\beta 1$

\section{Introduction}

The cells that comprise the gastrointestinal (GI) epithelium are continuously exposed to a variety of microorganisms, nutrients, and antigens. These cells must be able to distinguish between beneficial and pathogenic commensal and transient microbiota (Dwinell et al. 2003; Muller et al. 2005), as well as bacterial breakdown products and food antigens (Arnett and Viney 2009). To achieve this goal, the intestinal mucosa must develop a degree of immunological tolerance to the enormous bacterial burden present in the gut (Duerkop et al. 2009). However, in the face of GI infection, a quick and sufficient immune response is necessary to eliminate pathogens in order to prevent systemic disease (Eckmann 2006). These responses must be well-modulated in order to 
minimize inflammation so that the absorptive function of the GI epithelium is maintained. Prolonged inflammation in the GI tract as a result of pathogenic infection or exposure to inflammatory antigens can lead to significant destruction of the intestinal epithelia, causing reduced absorptive capacity, malnutrition, and impairment of growth. (Lunn 2000).

The protein lysozyme is an important non-specific antimicrobial factor in many body secretions including milk, saliva, and intestinal mucus. It also possesses the ability to modulate the inflammatory response through several mechanisms (Goldman et al. 1986). Lysozyme binds lipopolysaccharides (LPS), lipoteichoic acid (LTA), and peptidoglycan, preventing them from interacting with receptors on intestinal epithelial cells (IEC's) and intestinal macrophages (Ginsburg 2002; Ohno and Morrison 1989a). Sequestration of LPS by lysozyme suppresses pro-inflammatory effects, including production of TNF- $\alpha$ (Ohno and Morrison 1989b; Kurasawa et al. 1996; Takada et al. 1994a, b). Using a porcine model of chemically induced colitis, investigators were able to decrease expression of pro-inflammatory cytokines, including TNF- $\alpha$ and IL-8, as well as increase expression of anti inflammatory cytokines, including TGF- $\beta 1$, through oral administration of hen egg white lysozyme (Lee et al. 2009). Lysozyme also has significant immunomodulatory effects on neutrophils, decreasing several responses to pro-inflammatory agents and decreases oxidative metabolism in neutrophils without suppressing phagocytosis (Gordon et al. 1979).

Ruminants naturally produce extremely low levels of lysozyme in their milk however; our laboratory has created transgenic dairy goats that produce approximately two thirds the amount of lysozyme produced in human milk (Maga et al. 2006a). The human lysozyme (hLZ)-containing milk produced by these goats has been proven active against E.coli and other bacteria during both in vitro (Maga et al. 2006b) and in vivo studies (Maga et al. 2006c). In addition, feeding pasteurized hLZ milk to young pigs resulted in improved gastrointestinal tract morphology without raising levels of white blood cells (Brundige et al. 2008) as well as beneficially changing the serum metabolome (Brundige et al. 2009). The modulation of gut microbiota induced by consumption of hLZ milk therefore has the potential to influence intestinal immune response function.
Gut microbiota play a major role in the development and maturation of the innate and adaptive immune systems in the intestinal epithelium. Commensal bacteria can exert a protective effect on the gut by blocking activation of pro-inflammatory pathways such as the NF- $\kappa \mathrm{B}$ pathway (Schottelius and Baldwin 1999; Mumy and McCormick 2005; Duerkop et al. 2009), as well as activating the $\mathrm{I} \kappa \mathrm{B}$ pathway, which inhibits NF- $\kappa$ B (Sharma and Tepas 2010). NF- $\kappa \mathrm{B}$ is an immediate, early-response transcription factor that can be activated by pathogenic bacteria and bacterial breakdown products such as LPS (Lallès 2010). When activated, NF- $\kappa \mathrm{B}$ induces the expression of chemokine and cytokine genes, including IL-8 and TNF- $\alpha$ (Li and Stark 2002).

The pro-inflammatory cytokine TNF- $\alpha$ decreases tight junction barrier function in IEC's (Turner 2009), which activates the leak pathway, thereby allowing large solutes, including LPS, to pass through the tight junctions and activate the NF- $\kappa \mathrm{B}$ pathway, further increasing the inflammatory response (Turner 2009). Il-8, another pro-inflammatory cytokine, attracts macrophages, neutrophils, polymorphonuclear leukocytes (PMNs), and phagocytes as a first step in recruitment and induction of an inflammatory response (Dwinell et al. 2003). When activated, intestinal macrophages and phagocytes can also release proteases, oxygen radicals, and nitrogen metabolites (e.g. $\mathrm{NO}_{2}{ }^{-}$) which can cause damage to the intestine (Pathmakanthan and Hawkey 2000).

Cytokines are also responsible for dampening proinflammatory signals, especially TGF- $\beta 1$ (Sharma and Tepas 2010). TGF- $\beta 1$, or transforming growth factor $\beta 1$, is involved in multiple biological processes such as cell proliferation, migration, differentiation, extra cellular matrix deposition, and immune regulation (Brenmoehl et al. 2009). TGF- $\beta 1$ causes differentiation of $\mathrm{T}$ regulatory $\left(\mathrm{T}_{\text {reg }}\right)$ cells, which negatively regulate immunity. It also inhibits $\mathrm{NK}$ cells, mast cells, granulocytes and macrophages. Recently TGF$\beta 1$, in conjunction with IL-6, has been shown to be necessary for Th17 cell differentiation. Th17 cells are highly active during an inflammatory response. The functions of $\mathrm{T}_{\text {reg }}$ and Th17 cells are opposite, one being involved in immune tolerance and the other in inflammation. The regulatory pathways that TGF- $\beta 1$ modulates to control differentiation of these two immune cell types are currently being explored (Awasthi and Kuchroo 2009; Yoshimura et al. 2010). 
In order to investigate the effects of hLZ transgenic goats' milk on the intestinal immune response, multiple feeding studies were conducted in pigs, as they share a similar gastrointestinal morphology and physiology to humans and therefore are an attractive model (Domeneghini et al. 2006; Blachier et al. 2007). Gastrointestinal morphology and cytokine levels in pro- and anti-inflammatory pathways were analyzed to determine the effects of consumtion of hLZ-containing milk on villus morphology and immune regulation in the small intestine.

\section{Materials and methods}

Animals, necropsy, and sample collection

Samples from four separate feeding trials were analyzed for this study. Details of each feeding trial are outlined in Table 1. Pigs were kept in a temperature-controlled environmental chamber between 25 and $27^{\circ} \mathrm{C}$ for the course of the trial. Pigs were monitered twice daily for physical and general wellbeing. The diet and rearing of the pigs used for this study has been previously described (Brundige et al. 2008). Pigs from the 2004, 2006, and 2008 trials were fed $250 \mathrm{~mL}$ of hLZ-containing or control milk twice daily. Pigs from the 2009 study were fed $250 \mathrm{~mL}$ of either hLZ-containing or control milk twice daily for 1 week, then brought up to $350 \mathrm{~mL}$ twice daily for the remainder of the study. Milk samples were collected weekly for western blot analysis to confirm hLZ protein level. Care and milking of goats has also been previously described (Brundige et al. 2008). All animals were cared for under Association for Assessment and Accreditation of Laboratory Animal Care International (AAALAC) approved conditions.

Table 1 Pig ages and study durations for the 4 separate feeding trials

\begin{tabular}{llll}
\hline Year & $\begin{array}{l}\text { Number of pigs } \\
\text { in each group }\end{array}$ & $\begin{array}{l}\text { Age in days } \\
\text { at start of study }\end{array}$ & $\begin{array}{l}\text { Days } \\
\text { fed }\end{array}$ \\
\hline 2004 & 4 & 14 & 15 \\
2006 & 6 & 14 & 42 \\
2008 & 3 & 14 & 25 \\
2009 & 4 & 54 & 15 \\
\hline
\end{tabular}

At the end of each trial, pigs were weighed and necropsied by an American College of Veterinary Pathologist (ACVP) board-certified animal pathologist at the California Animal Health and Food Safety (CAFHS) laboratory (UC Davis, Davis, CA, USA). The necropsy procedure, including euthanasia of animals, collection of tissue samples from the upper and lower intestine, and preparation of slides for histological analysis has been previously described (Brundige et al. 2008). Tissue samples to be used for qRT-PCR analysis were snap frozen in liquid nitrogen before being stored at $-70^{\circ} \mathrm{C}$ until RNA extraction.

\section{Histology}

Slides from pigs in the 2008 and 2009 feeding trials were analyzed by photographing then measuring the villi height, width, lamina propria thickness, and crypt depth at $10 \times$ magnification, using Spot Advanced Software (v3.4, Diagnostic Instruments). In addition, the number of lymphocytes and goblet cells per villus were counted at $40 \times$ magnification and analyzed as cells per unit villous height. Four to six villi were measured per slide. SAS statistical software (SAS, Cary, NC, USA) was used to perform statistical analysis. Tukey's test was used determine $P$-values and standard errors. A $P$ value of $\leq 0.05$ is considered statistically significant.

RNA preparation and cDNA synthesis

Total RNA was isolated from the duodenum and ileum samples from each animal from the 2004, 2006, 2008, and 2009 feeding trials using Trizol Reagent (Invitrogen, Carlsbad, CA, USA) per manufacturer's instructions. RNA was quantified by spectrophotometry and quality was determined by running $1 \mu \mathrm{g}$ of RNA on a $1 \%$ MOPS/formaldehyde agarose gel.

For each sample used for cDNA synthesis, $1 \mu \mathrm{g}$ of RNA was combined with a master mix containing OligoDT $_{(18)}, 5 \times$ RT Buffer (Invitrogen), 0.1 M DTT, RNasin, dNTPs, DNaseI, and DEPC $\mathrm{dH}_{2} \mathrm{O}$. Samples were first DNase-treated to remove any residual DNA by heating for $1 \mathrm{~h}$ at $37^{\circ} \mathrm{C}$, followed by heating for $10 \mathrm{~min}$ at $70^{\circ} \mathrm{C}$ to denature the DNase enzyme. SuperScriptII reverse transcriptase (Invitrogen) was then added for cDNA synthesis by heating at $40^{\circ} \mathrm{C}$ for 
Table 2 Genes and primer sequences

\begin{tabular}{|c|c|c|c|c|}
\hline $\begin{array}{l}\text { Gene } \\
\text { symbol }\end{array}$ & Gene name & $\begin{array}{l}\text { Accession } \\
\text { number }\end{array}$ & Primer sequences & $\begin{array}{l}\text { Amplicon } \\
\text { size (bp) }\end{array}$ \\
\hline RPL4 & Ribosomal Protein L4 & DQ845176 & $\begin{array}{l}\text { Fwd: CGATGCCACGCAAGAAGATTCAT[FC]G } \\
\text { Rev: GCATTGTCTTTGCATACGGGTTTA }\end{array}$ & 99 \\
\hline TBP & TATA Box Binding Protein & DQ845178 & $\begin{array}{l}\text { Fwd: CGGGCATGAGAATAAGAGAACCC[FC]G } \\
\text { Rev: TCTTGCTGCTAGTCTGGACTGTTC }\end{array}$ & 107 \\
\hline IL-8 & Interlukin-8 & NM_213867 & $\begin{array}{l}\text { Fwd: CGGGGAGACTAGAAAGAAAACAGCC[FC]G } \\
\text { Rev: GCGTATTTATGCACTGGCATCG }\end{array}$ & 152 \\
\hline TGF- $\beta 1$ & Transforming Growth Factor b1 & AF461808 & $\begin{array}{l}\text { Fwd: CGGACTACTACGCCAAGGAGGT } \\
\text { Rev: CGGAAGAGAGAGCAATACAGGTTC[FC]G }\end{array}$ & 158 \\
\hline TNF- $\alpha$ & Tumor Necrosis Factor & X57321 & $\begin{array}{l}\text { Fwd: CCCTTGAGCATCAACCCTCTG } \\
\text { Rev: CGTTGTGCTTTGACATTGGCTACAA[FC]G }\end{array}$ & 98 \\
\hline
\end{tabular}

${ }^{\text {a }}$ With additional sequence from the DFCI Gene Index Project; $[\mathrm{FC}]=$ FAM-labeled cytosine

$1 \mathrm{~h}$ followed by heating to $70^{\circ} \mathrm{C}$ for 10 min to destroy any remaining enzyme. All resulting cDNA samples were stored at $-70^{\circ} \mathrm{C}$ until used.

Genes and primers

Two genes, Ribosomal Protein L4 (RPL4) (GenBank\# DQ845176) and TATA Box Binding Protein (TBP) (GenBank\# DQ845178), were chosen as reference genes as both of these genes show stable expression in the small intestine of pigs (Nygard et al. 2007). RPL4 was used as reference for high copy number transcripts while TBP was used for low copy number transcripts. Three target genes involved in the inflammatory response were selected for evaluation: pro-inflammatory cytokines TNF- $\alpha$ (GenBank\# X57321) and IL-8 (GenBank\# NM_213867) and the anti-inflammatory cytokine TGF- $\beta 1$ (GenBank\# AF461808). TNF- $\alpha$ was selected because of the demonstrated ability of lysozyme to interfere with its activity. IL-8 was chosen because of its critical role as a chemoattractant in inflammatory responses. TGF- $\beta 1$ was chosen because it is a major cytokine in the GI tract.

Invitrogen LUX primers were designed using GenBank porcine sequences and Invitrogen Lux primer design software. Due to an incomplete GenBank sequence, additional sequence for use in designing primers for TBP was obtained by using a Blast search with the available GenBank sequence against the DFCI Gene Index Project (http://compbio.dfci. harvard.edu/tgi/) pig indices. All primers were designed to span introns and yield products that were at least 98 bp in length. Primer sets were labeled with FAM dye (Table 2).

Real time qPCR conditions

All qPCR reactions were run in 96-well plates on an ABI 7500 fast thermocycler. Each reaction contained $10 \mu \mathrm{l}$ of $2 \times$ Fast SYBR Green (Applied Biosystems, Foster City, CA, USA) probe master mix, $1 \mu \mathrm{l}$ of $10 \mu \mathrm{M}$ reverse primer, $1 \mu \mathrm{l}$ of $10 \mu \mathrm{M}$ forward primer, cDNA and $\mathrm{dH}_{2} \mathrm{O}$ in a total sample volume of $20 \mu \mathrm{l}$. Standard curves for each gene were constructed using cDNA template consisting of pooled cDNA from different pigs at concentrations of $300 \mathrm{ng} /$ reaction with 1:2 dilutions down to $4.68 \mathrm{ng} /$ reaction. Three standard curves were generated in three different qPCR runs for each gene. To determine gene expression in each experimental sample, a total of 50 ng cDNA was used with target genes being run on the same plate as the reference genes.

Each 96-well plate was run using a 2-stage thermocycling program. Amplification was carried out in stage 1 and consisted of 3 steps: denaturation for $15 \mathrm{~s}$ at $94^{\circ} \mathrm{C}$, annealing for $30 \mathrm{~s}$ at $60^{\circ} \mathrm{C}$, and product extension for $30 \mathrm{~s}$ at $72^{\circ} \mathrm{C}$. Fluorescence data was collected on the annealing step. Stage 1 was repeated for a total of 40 cycles. In stage 2 , dissociation was measured in 3 steps: $95^{\circ} \mathrm{C}$ for $15 \mathrm{~s}, 60^{\circ} \mathrm{C}$ for $1 \mathrm{~min}$, and $95^{\circ} \mathrm{C}$ for $15 \mathrm{~s}$. For each plate, threshold and baseline were individually set and $\mathrm{C}_{\mathrm{T}}$ values determined using the 7500 Fast software. 
Table 3 Histological measurements $(\mu \mathrm{M})$ from the duodenum and ileum of pigs fed either pasteurized control milk or milk containing hLZ

\begin{tabular}{llcccr}
\hline & Number of villi $^{\mathrm{a}}$ & Villus height & Villus width & Crypt depth & Lamina Propria \\
\hline $\begin{array}{l}\text { Duodenum } \\
\text { Control }(\mathrm{n}=7)\end{array}$ & 36 & & & & \\
$\mathrm{hLZ}(\mathrm{n}=7)$ & 32 & $579.03 \pm 26.09$ & $171.78 \pm 7.44$ & $97.26 \pm 9.78$ & $237.37 \pm 24.25$ \\
$P$ value & & $631.29 \pm 27.34$ & $167.62 \pm 6.86$ & $105.27 \pm 11.78$ & $171.88 \pm 10.99$ \\
Ileum & $\mathbf{0 . 0 9 2 3}$ & 0.6693 & 0.5474 & $\mathbf{0 . 0 0 0 1 *}$ \\
Control $(\mathrm{n}=7)$ & 52 & & & & \\
hLZ $(\mathrm{n}=7)$ & 45 & $440.14 \pm 13.56$ & $149.38 \pm 4.83$ & $71.68 \pm 5.55$ & $183.99 \pm 11.51$ \\
$P$ value & & $420.52 \pm 13.56$ & $146.14 \pm 6.27$ & $67.89 \pm 6.17$ & $163.63 \pm 11.47$ \\
\hline
\end{tabular}

* Denotes significance with a $P$ value $\leq 0.05$

${ }^{\text {a }}$ Number of villi counted for each group of animals

Triplicate $C_{T}$ values were averaged for use in calculations and statistics.

Quantitation analysis and statistics

Relative expression levels of each target gene and fold differences in expression between the different experimental groups for the duodenum and ileum were calculated in a pair-wise fashion using the Pfaffl method with REST-MCS software (Pfaffl et al. 2002). Briefly, the efficiency of each primer pair was calculated from standard curve data. Each target gene was normalized to TBP to determine pair-wise fold differences in expression because TBP showed the most consistent expression across studies. $P$-values and standard errors for fold expression differences were also calculated using REST-MCS software.

\section{Results}

Histology

There were no significant differences between different years within feeding groups for the histological measurements; therefore data was pooled for analysis. There were no significant differences between the hLZ fed and control fed animals for the majority of the histological parameters measured (Table 3). In the duodenum, hLZ fed animals had significantly thinner lamina propria $(P=0.0001)$ and tended to have longer villi $(P=0.0923)$. Differences between years were observed in the lymphocyte and goblet cells, thus data was analyzed separately (Table 4). In the duodenum lymphocytes were significantly increased in hLZ fed animals in the 2008 study $(P=0.009)$, while in the ileum, the $2008 \mathrm{hLZ}$ fed pigs had significantly decreased numbers of lymphocytes $(P=0.038)$. However in the 2009 study, the hLZ fed pigs had significantly more lymphocytes $(P=0.013)$ when compared to the controls. No significant changes in goblet cells were observed, however, in 2008 pigs fed hLZ milk tended to have more goblet cells in the ileum $(P=0.055)$.

\section{Quantitative real time PCR}

There were no significant differences between different years within feeding groups for the cytokines and data was pooled for analysis. Relative expression rates of the three cytokines investigated are presented in Table 5 with $C_{T}$ values that were adjusted using TBP as a reference gene. Consumption of hLZ milk resulted in a significant increase in expression of the anti-inflammatory cytokine TGF- $\beta 1$ in the ileum $(P=0.047)$, but did not affect expression levels of TNF- $\alpha$ or IL- 8 in the duodenum or ileum.

\section{Discussion}

These experiments were done to expand and confirm our previous results (Brundige et al. 2008) in order to establish the general safety, and to quantify the effects of feeding goat's milk containing hLZ on key 
Table 4 Numbers of lymphocytes and goblet cells per unit of villous height in the duodenum and ileum of young pigs from the 2008 and 2009 feeding trials

\begin{tabular}{|c|c|c|c|c|c|c|c|c|}
\hline Year & Area of the gut & Number of villi ${ }^{\mathrm{a}}$ & Lymphocytes/ $\mu \mathrm{M}$ & villi height & $P$ value & Goblet cells/ $\mu \mathrm{M}$ & villi height & $P$ value \\
\hline \multirow[t]{4}{*}{2008} & \multirow[t]{2}{*}{ Duodenum } & 18 & Control $(\mathrm{n}=3)$ & $0.144 \pm 0.008$ & \multirow[t]{2}{*}{$0.009 *$} & Control $(\mathrm{n}=3)$ & $0.014 \pm 0.001$ & \multirow[t]{2}{*}{0.207} \\
\hline & & 16 & $\operatorname{hLZ}(\mathrm{n}=3)$ & $0.177 \pm 0.009$ & & $\mathrm{hLZ}(\mathrm{n}=3)$ & $0.017 \pm 0.002$ & \\
\hline & \multirow[t]{2}{*}{ Ileum } & 26 & Control $(\mathrm{n}=3)$ & $0.168 \pm 0.008$ & \multirow[t]{2}{*}{ 0.038* } & Control $(\mathrm{n}=3)$ & $0.035 \pm 0.003$ & \multirow[t]{2}{*}{0.055} \\
\hline & & 21 & $\mathrm{hLZ}(\mathrm{n}=3)$ & $0.146 \pm 0.007$ & & $\mathrm{hLZ}(\mathrm{n}=3)$ & $0.042 \pm 0.007$ & \\
\hline \multirow[t]{4}{*}{2009} & \multirow[t]{2}{*}{ Duodenum } & 18 & Control $(n=4)$ & $0.195 \pm 0.011$ & \multirow[t]{2}{*}{0.446} & Control $(n=4)$ & $0.035 \pm 0.003$ & \multirow[t]{2}{*}{0.891} \\
\hline & & 16 & $\operatorname{hLZ}(\mathrm{n}=4)$ & $0.207 \pm 0.013$ & & hLZ $(n=4)$ & $0.035 \pm 0.004$ & \\
\hline & \multirow[t]{2}{*}{ Ileum } & 26 & Control $(n=4)$ & $0.163 \pm 0.013$ & \multirow[t]{2}{*}{ 0.013* } & Control $(n=4)$ & $0.036 \pm 0.003$ & \multirow[t]{2}{*}{0.352} \\
\hline & & 24 & $\mathrm{hLZ}(\mathrm{n}=4)$ & $0.202 \pm 0.010$ & & $\mathrm{hLZ}(\mathrm{n}=4)$ & $0.041 \pm 0.004$ & \\
\hline
\end{tabular}

* Denotes significance with a $P$ value $\leq 0.05$

${ }^{\text {a }}$ Number of villi counted for each group of animals

Table 5 Levels of cytokines TNF $\alpha$, IL-8, and TGF- $\beta 1$ in the duodenum and ileum of pigs fed with hLZ-containing milk, or control milk

\begin{tabular}{|c|c|c|c|c|c|}
\hline Gene name & Area of the gut & Number of animals & TBP adjusted $\mathrm{CT}$ value & $P$ value & $\begin{array}{l}\text { Fold change } \\
\text { in expression }\end{array}$ \\
\hline \multirow[t]{4}{*}{$\mathrm{TNF} \alpha$} & \multirow[t]{2}{*}{ Duodenum } & Control $\mathrm{n}=17$ & $31.582 \pm 0.462$ & \multirow[t]{2}{*}{0.1876} & \multirow[t]{2}{*}{ NA } \\
\hline & & $\mathrm{hLZ} \mathrm{n}=17$ & $32.394 \pm 0.428$ & & \\
\hline & \multirow[t]{2}{*}{ Ileum } & Control $\mathrm{n}=17$ & $32.662 \pm 0.332$ & \multirow[t]{2}{*}{0.1177} & \multirow[t]{2}{*}{ NA } \\
\hline & & $\mathrm{hlZ} \mathrm{n}=17$ & $31.951 \pm 0.331$ & & \\
\hline \multirow[t]{4}{*}{ IL-8 } & \multirow[t]{2}{*}{ Duodenum } & Control $\mathrm{n}=17$ & $28.381 \pm 0.353$ & \multirow[t]{2}{*}{0.8427} & \multirow[t]{2}{*}{ NA } \\
\hline & & $\mathrm{hLZ} \mathrm{n}=17$ & $28.473 \pm 0.327$ & & \\
\hline & \multirow[t]{2}{*}{ Ileum } & Control $\mathrm{n}=17$ & $28.156 \pm 0.237$ & \multirow[t]{2}{*}{0.538} & \multirow[t]{2}{*}{ NA } \\
\hline & & $\mathrm{hLZ} \mathrm{n}=17$ & $27.961 \pm 0.236$ & & \\
\hline \multirow[t]{4}{*}{ TGF- $\beta 1$} & \multirow[t]{2}{*}{ Duodenum } & Control $\mathrm{n}=17$ & $27.876 \pm 0.603$ & \multirow[t]{2}{*}{0.6704} & \multirow[t]{2}{*}{ NA } \\
\hline & & $\mathrm{hLZ} \mathrm{n}=17$ & $29.146 \pm 0.559$ & & \\
\hline & \multirow[t]{2}{*}{ Ileum } & Control $\mathrm{n}=17$ & $28.269 \pm 0.179$ & \multirow[t]{2}{*}{$0.0478^{*}$} & \multirow[t]{2}{*}{$0.492 \uparrow$} \\
\hline & & $\mathrm{hLZ} \mathrm{n}=17$ & $27.777 \pm 0.178$ & & \\
\hline
\end{tabular}

* Denotes significance with a $P$ value $\leq 0.05$

markers of immune function in the small intestinal epithelium of healthy pigs. We found through measuring key cytokine levels and evaluating histology in the pigs' small intestine that the hLZ-containing milk did not induce an inflammatory response in the gut and improved some parameters associated with gastrointestinal health. Specifically, we found higher expression of TGF- $\beta 1$, an anti-inflammatory cytokine, and increased intestinal surface area in pigs fed milk containing hLZ. Younger pigs from the 2008 study had an increased number of intraepithelial lymphocytes (IEL's) per $\mu \mathrm{M}$ villus height in the duodenum, but a decreased number in the ileum as opposed to older pigs from the 2009 study which had increased lymphocytes in the ileum. Pigs fed hLZ in 2008 tended to have more goblet cells per unit villus height in the ileum.

Finding significant increases in intraepithelial lymphocytes (IEL) in the duodenum of older pigs fed hLZ milk is consistent with other studies. Pathogen free chickens given a mix of antimicrobial peptides also had significantly more IEL's in their duodenum when compared to controls (Wang et al. 2009). This demonstrates that increases in IEL's are an indication of a well-primed and healthy gut and IEL numbers can be raised with application of antimicrobial peptides. Finding decreased lymphocytes in younger hLZ fed pigs also is consistent with 
previously reported results from feeding hLZ-containing milk to young pigs (Brundige et al. 2008) and hLZ-containing rice to chicks (Humphrey et al. 2002). In both of these studies, the decreases in IEL's were attributed to there being fewer microbial challenges in the GI tract due to the antimicrobial nature of hLZ. It has long been established that animals fed antibiotics have thin intestinal walls with few IEL's, presumptively due to antibiotics reducing microbiota populations and thus the stimulation of the immune system (Berman and Weinstein, 1971). We believe that differing results between the 2008 and 2009 cohorts are due to the different ages of animals used in the two studies. As animals age, their immune systems mature and increasing populations of IEL's are seen (Ishimoto et al. 2004). IEL numbers in the intestine of pigs have been shown to increase by a factor of 12 between day 1 and day 60 of life (Pabst and Rothkötter, 1999). We hypothesize that the lower IEL counts seen in the younger hLZ-fed pigs are indicative of an advantageous decrease in microbial challenges in the GI tract during early life, when the neonate's immune system has not yet fully developed. However, as the pigs aged, we believe that feeding hLZ milk caused IEL populations in the gut to increase at a faster rate than in the controls, producing a more mature immune system at an earlier age. It is well known that breastfed infants experience fewer gastrointestinal illnesses than bottle-fed infants (Ip et al. 2007) and that breastfeeding aids in the development of the intestinal mucosa and immune system (Mountzouris et al. 2002; Newburg and Walker 2007). The results of our current and previous work (Brundige et al. 2008), taken together, support hLZ-containing milk as lowering microbial challenges and enhancing the maturation of the immune system in the gut. However, further work needs to be completed in order to fully understand how hLZcontaining milk affects the development of the IEL population in the intestine as the animal ages.

Pigs fed hLZ in 2008 tended to have more goblet cells per unit villus height in the ileum. Wang et al. (2009) also found an increase in goblet cells in the ileum. Goblet cells produce the protective mucus layer that lines the intestine and is the first defense against pathogenic bacteria (Duerkop et al. 2009). An increase in goblet cells indicates an increased ability to produce mucin, and thus protect the intestinal epithelium. Histological data showed hLZ fed pigs had significantly thinner lamina propria in the duodenum and also tended to have taller villi in the ileum. The thinning of the lamina propria is also consistent with other studies done on the effects of lysozyme on gut health. Chickens fed transgenic rice containing lysozyme also had significantly thinner lamina propria, as well as significantly higher feed efficiency (Humphrey et al. 2002). A thinner lamina propria is thought to be associated with increased intestinal absorption and growth (Berman and Weinstein 1971).

The levels of three cytokines were investigated and for both IL- 8 and TNF- $\alpha$ there was no statistically significant difference between levels in hLZ and control milk fed pigs. TNF- $\alpha$ is a strong proinflammatory cytokine whose expression is greatly increased during inflammation and infection. Elevated levels of TNF- $\alpha$ can cause diarrhea, tissue damage, and decreased digestive enzyme expression (Turner 2009; Peuhkuri et al. 2010). Feeding hLZcontaining milk to pigs did not increase the level of TNF- $\alpha$ production, showing that consumption of the milk did not induce an inflammatory response. The pro-inflammatory cytokine IL- 8 was also investigated with the same finding. Pigs fed pasteurized hLZ milk did not have elevated levels of TNF- $\alpha$ or IL- 8 , supporting our conclusion that hLZ milk does not cause inflammation.

We found that feeding hLZ milk significantly increased levels of the anti-inflammatory cytokine TGF- $\beta 1$ in the ileum. This is consistent with the findings of Lee et al. in 2009. They administered hen egg derived lysozyme (HEL) to pigs with chemically induced colitis, as well as healthy pigs. The healthy pigs supplemented with HEL had significantly higher levels of TGF- $\beta 1$ than non-supplemented healthy pigs. Although TGF- $\beta 1$ is necessary for differentiation of pathogenic Th17 cells, recent studies indicate that heightened levels of TGF- $\beta 1$ induces increased levels of Foxp3, which reduces Th17 cell differentiation (Zhou et al. 2008; Lee et al. 2009).

Elevated levels of TGF- $\beta 1$ in the ileum may give clues as to the mechanism by which lysozyme modulated this cytokine. Consumption of hLZ milk by pigs has been shown to significantly alter bacteria populations in the small intestine (Maga et al. 2006c; Brundige et al. 2008). There is a growing body of evidence that commensal bacteria have an important role in modulating cytokine levels and thus 
inflammatory response (Duerkop et al. 2009; Lallès 2010; Sharma and Tepas 2010; Shimizu 2010). Changes in bacterial populations caused by hLZ could cause an increase in TGF- $\beta 1$ expression, further protecting the gut from inflammation. Preliminary data from the 2009 feeding trial suggests pigs fed hLZ milk had increased numbers of Lactobacillaceae and Bifidobacteriacea (unpublished data), both of which are considered biomarkers of increased gut health (Bourlioux et al. 2003). Administration of Lactobacillaceae has previously been found to increase levels of TGF- $\beta 1$ in the intestine (Wallace et al. 2003; Torii et al. 2007). This supports our hypothesis that lysozyme exerts a protective effect on the gut by modulating the levels of commensal bacteria, which in turn modulate cytokine pathways, however further studies must be done to confirm this.

The goal of this study was to investigate the effects of hLZ milk on immune response in the intestine and to confirm that the consumption of pasteurized hLZ containing goats' milk does not cause an inflammatory response, using a porcine model. The hLZ milk did not cause increased expression of pro-inflammatory cytokines TNF- $\alpha$ or IL-8, which supports our hypothesis. It also increased IEL's and goblet cells, two cell types that are part of the first line of defense in the gut, creating an intestinal epithelial layer that is better prepared to protect against pathogenic bacteria. Finally, hLZ significantly increased production of anti-inflammatory cytokine TGF- $\beta 1$ in the ileum. All of these changes suggest that the consumption of pasteurized hLZ improves the overall gastrointestinal health of the growing pig.

Acknowledgments We wish to thank Kent Parker and the UC-Davis Swine facility staff for assistance with pig rearing and Jan Carlson and the UC-Davis Goat Barn staff for care and milking of dairy goats. Thanks to Stoyan Petkov for his advice on qRT-PCR protocols and statistical analysis and Gretchen Sturm and Teal Miller who helped in the examination of histological slides. We also thank Wyatt Delfino and Kathryn Jackson for help with tissue sample collection for qRT-PCR. We would also like to thank the USDA for funding this project (BRAG Project \#2008-03039).

Open Access This article is distributed under the terms of the Creative Commons Attribution Noncommercial License which permits any noncommercial use, distribution, and reproduction in any medium, provided the original author(s) and source are credited.

\section{References}

Arnett HA, Viney JL (2009) Recent developments in IBD and the B7 family of costimulatory molecules. Curr Opin Investig Drugs 10:443-451

Awasthi A, Kuchroo VK (2009) Th17 cells: from precursors to players in inflammation and infection. Int Immunol 21:489-498

Berman HA, Weinstein L (1971) Antibiotics and nutrition. Am J Clin Nutr 24:260-264

Blachier F, Vaugelade P, Robert V, Kibangou B, CanonneHergaux F, Delpal S, Bureau F, Blottière H, Bouglé D (2007) Comparative capacities of the pig colon and duodenum for luminal iron absorption. Can J Physiol Pharmacol 85:185-192

Bourlioux P, Koletzko B, Guarner F, Braesco V (2003) The intestine and its microflora are partners for the protection of the host: report on the Danone symposium "The intelligent intestine", held in Paris, June 14, 2002. Am J Clin Nutr 78:675-683

Brenmoehl J, Miller SN, Hofmann C, Vogl D, Falk W, Schölmerich J, Rogler G (2009) Transforming growth factor-beta 1 induces intestinal myofibroblast differentiation and modulates their migration. World J Gastroenterol 15:1431-1442

Brundige DR, Maga EA, Klasing KC, Murray JD (2008) Lysozyme transgenic goats' milk influences gastrointestinal morphology in young pigs. J Nutr 138:921-926

Brundige DR, Maga EA, Klasing KC, Murray JD (2009) Consumption of pasteurized human lysozyme transgenic goats' milk alters serum metabolite profile in young pigs. Transgenic Res 19:563-574

Domeneghini C, Di Giancamillo A, Arrighi S, Bosi G (2006) Gut-trophic feed additives and their effects upon the gut structure and intestinal metabolism. State of the art in the pig, and perspectives towards humans. Histol Histopathol 21:273-283

Duerkop BA, Vaishnava S, Hooper LV (2009) Immune responses to the microbiota at the intestinal mucosal surface. Immunity 31:368-376

Dwinell MB, Johanesen PA, Smith JM (2003) Immunobiology of epithelial chemokines in the intestinal mucosa. Surgery 133:601-607

Eckmann L (2006) Sensor molecules in intestinal innate immunity against bacterial infections. Curr Opin Gastroenterol 22:95-101

Ginsburg I (2002) Role of lipoteichoic acid in infection and inflammation. Lancet Infect Dis 2:171-179

Goldman AS, Thorpe LW, Goldblum RM, Hanson LA (1986) Anti-inflammatory properties of human milk. Acta Paediatr Scand 75:689-695

Gordon LI, Douglas SD, Kay NE, Yamada O, Osserman EF, Jacob HS (1979) Modulation of neutrophil function by lysozyme. Potential negative feedback system of inflammation. J Clin Invest 64:226-232

Humphrey BD, Huang N, Klasing KC (2002) Rice expressing lactoferrin and lysozyme has antibiotic-like properties when fed to chicks. J Nutr 132:1214-1218

Ishimoto $\mathrm{Y}$, Tomiyama-Miyaji $\mathrm{C}$, Watanabe $\mathrm{H}$, Yokoyama $\mathrm{H}$, Ebe K, Tsubata S, Aoyagi Y, Abo T (2004) Age- 
dependent variation in the proportion and number of intestinal lymphocyte subsets, especially natural killer $\mathrm{T}$ cells, double-positive CD4+ CD8 + cells and B220+ T cells, in mice. Immunology 113:371-377

Kurasawa T, Takada K, Ohno N, Yadomae T (1996) Effects of murine lysozyme on lipopolysaccharide-induced biological activities. FEMS Immunol Med Microbiol 13:293-301

Lallès JP (2010) Intestinal alkaline phosphatase: multiple biological roles in maintenance of intestinal homeostasis and modulation by diet. Nutr Rev 68:323-332

Lee M, Kovacs-Nolan J, Yang C, Archibold T, Fan MZ, Mine Y (2009) Hen egg lysozyme attenuates inflammation and modulates local gene expression in a porcine model of dextran sodium sulfate (DSS)-induced colitus. J Agric Food Chem 57:2233-2240

Li X, Stark GR (2002) NFkappaB-dependent signaling pathways. Exp Hematol 30:285-296

Lunn PG (2000) The impact of infection and nutrition on gut function and growth in childhood. Proc Nutr Soc 59:147-154

Maga EA, Shoemaker CF, Rowe JD, Bondurant RH, Anderson GB, Murray JD (2006a) Production and processing of milk from transgenic goats expressing human lysozyme in the mammary gland. J Dairy Sci 89:518-524

Maga EA, Cullor JS, Smith W, Anderson GB, Murray JD (2006b) Human lysozyme expressed in the mammary gland of transgenic dairy goats can inhibit the growth of bacteria that cause mastitis and the cold-spoilage of milk. Foodborne Pathog Dis 3:384-392

Maga EA, Walker RL, Anderson GB, Murray JD (2006c) Consumption of milk from transgenic goats expressing human lysozyme in the mammary gland results in the modulation of intestinal microflora. Transgenic Res 15:515-519

Mountzouris KC, McCartney AL, Gibson GR (2002) Intestinal microflora of human infants and current trends for its nutritional modulation. Br J Nutr 87:405-420

Muller CA, Autenrieth IB, Peschel A (2005) Innate defenses of the intestinal epithelial barrier. Cell Mol Life Sci 62:1297-1307

Mumy KL, McCormick BA (2005) Events at the host-microbial interface of the gastrointestinal tract. II. Role of the intestinal epithelium in pathogen-induced inflammation. Am J Physiol Gastrointest Liver Physiol 288:G854-G859

Newburg DS, Walker WA (2007) Protection of the neonate by the innate immune system of developing gut and of human milk. Pediatr Res 61:2-8

Nygard AB, Jorgensen CB, Cirera S, Fredholm M (2007) Selection of reference genes for gene expression studies in pig tissues using SYBR green qPCR. BMC Mol Biol 8:67

Ohno N, Morrison DC (1989a) Lipopolysaccharide interaction with lysozyme. Binding of lipopolysaccharide to lysozyme and inhibition of lysozyme enzymatic activity. J Biol Chem 264:4434-4441

Ohno N, Morrison DC (1989b) Lipopolysaccharide interactions with lysozyme differentially affect lipopolysaccharide immunostimulatory activity. Eur J Biochem 186:629_ 636

Pabst R, Rothkötter HJ (1999) Postnatal development of lymphocyte subsets in different compartments of the small intestine of piglets. Vet Immunol Immunopathol 72:167173

Pathmakanthan S, Hawkey CJ (2000) A lay doctor's guide to the inflammatory process in the gastrointestinal tract. Postgrad Med J 76:611-617

Peuhkuri K, Vapaatalo H, Korpela R (2010) Even low-grade inflammation impacts on small intestinal function. World J Gastroenterol 16:1057-1062

Pfaffl MW, Horgan GW, Dempfle L (2002) Relative expression software tool (REST) for group-wise comparison and statistical analysis of relative expression results in realtime PCR. Nucleic Acids Res 30:36

Schottelius AJ, Baldwin AS Jr (1999) A role for transcription factor NF-kappa $B$ in intestinal inflammation. Int $\mathrm{J}$ Colorectal Dis 14:18-28

Sharma R, Tepas JJ 3rd (2010) Microecology, intestinal epithelial barrier and necrotizing enterocolitis. Pediatr Surg Int 26:11-21

Shimizu M (2010) Interaction between food substances and the intestinal epithelium. Biosci Biotechnol Biochem 74:232241

Takada K, Ohno N, Yadomae T (1994a) Binding of lysozyme to lipopolysaccharide suppresses tumor necrosis factor production in vivo. Infect Immun 62:1171-1175

Takada K, Ohno N, Yadomae T (1994b) Detoxification of lipopolysaccharide (LPS) by egg white lysozyme. FEMS Immunol Med Microbiol 9:255-263

Torii A, Torii S, Fujiwara S, Tanaka H, Inagaki N, Nagai H (2007) Lactobacillus Acidophilus strain L-92 regulates the production of Th1 cytokine as well as Th2 cytokines. Allergol Int 56:293-301

Turner JR (2009) Intestinal mucosal barrier function in health and disease. Nat Rev Immunol 9:799-809

Wallace TD, Bradley S, Buckley ND, Green-Johnson JM (2003) Interactions of lactic acid bacteria with human intestinal epithelial cells: effects on cytokine production. J Food Prot 66:466-472

Wang D, Ma W, She R, Sun Q, Liu Y, Hu Y, Liu L, Yang Y, Peng K (2009) Effects of swine gut antimicrobial peptides on the intestinal mucosal immunity in specific-pathogenfree chickens. Poult Sci 88:967-974

Yoshimura A, Wakabayashi Y, Mori T (2010) Cellular and molecular basis for the regulation of inflammation by TGF-beta. J Biochem 147:781-792 